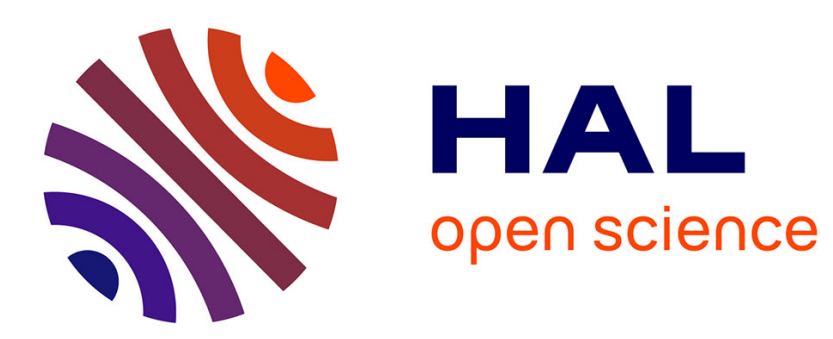

\title{
Experimental and numerical characterization of airflow in a closed refrigerated display cabinet using PIV and CFD techniques
}

\author{
N. Chaomuang, D. Flick, A. Denis, Onrawee Laguerre
}

\section{- To cite this version:}

N. Chaomuang, D. Flick, A. Denis, Onrawee Laguerre. Experimental and numerical characterization of airflow in a closed refrigerated display cabinet using PIV and CFD techniques. International Journal of Refrigeration, 2020, 111, pp.168-177. 10.1016/j.ijrefrig.2019.12.001 . hal-02609824

\section{HAL Id: hal-02609824 \\ https://hal.inrae.fr/hal-02609824}

Submitted on 16 May 2020

HAL is a multi-disciplinary open access archive for the deposit and dissemination of scientific research documents, whether they are published or not. The documents may come from teaching and research institutions in France or abroad, or from public or private research centers.
L'archive ouverte pluridisciplinaire HAL, est destinée au dépôt et à la diffusion de documents scientifiques de niveau recherche, publiés ou non, émanant des établissements d'enseignement et de recherche français ou étrangers, des laboratoires publics ou privés. 


\title{
Experimental and numerical characterization of airflow in a closed
}

\section{refrigerated display cabinet using PIV and CFD techniques}

\author{
Nattawut Chaomuang ${ }^{\mathrm{a}, \mathrm{b}, \mathrm{c}}$, Denis Flick $^{\mathrm{b}}$, Alain Denis ${ }^{\mathrm{a}}$, Onrawee Laguerre ${ }^{\mathrm{a}, *}$ \\ ${ }^{a}$ Irstea, UR FRISE, Refrigeration Process Engineering Research Unit, 1 rue Pierre-Gilles de Gennes, 92160 \\ Antony, France

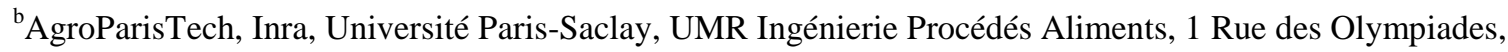 \\ 91300 Massy, France \\ ${ }^{c}$ Department of Food Engineering, King Mongkut's Institute of Technology Ladkrabang, Bangkok 10520, \\ Thailand \\ *Corresponding author: Onrawee Laguerre, Tel: +33 (0)1 409662 96, e-mail: onrawee laguerre @irstea.fr
}

\begin{abstract}
Air velocity measurements were carried out using the Particle Image Velocimetry (PIV) technique in a display cabinet under two configurations: closed and open doors. Two conditions (refrigeration system turned "on" and turned "off") were studied in the closed configuration. The airflow pattern was almost the same for both conditions. The air curtain was quite stable. In the upper part of the cabinet, air recirculation occurred, and this phenomenon induces external air infiltration through the door gaps. The air curtain in the open configuration (refrigeration system turned "off") was less stable than the closed configuration. Large unsteady eddies developed in the mixing layers, thereby promoting greater external air infiltration. A two-dimensional computational fluid dynamic (2D-CFD) model was developed and showed the ability to reproduce the main flow phenomena observed in the experiment. The trend of predicted product temperature profile was also in agreement with the experimental values, despite slight underestimation.
\end{abstract}

Keywords: Closed display cabinet; Air velocity; Experimental study; PIV; CFD 


\section{Journal Pre-proof}

\section{Nomenclature}

$A \quad$ area $\left[\mathrm{m}^{-2}\right]$

$C_{p} \quad$ specific heat $\left[\mathrm{J} \cdot \mathrm{kg}^{-1} \cdot \mathrm{K}^{-1}\right]$

$e \quad$ thickness [m]

$g$ gravitational acceleration $\left[\mathrm{m} \cdot \mathrm{s}^{-2}\right]$

$h \quad$ convective heat transfer coefficient $\left[\mathrm{W} \cdot \mathrm{m}^{-2} \cdot \mathrm{K}^{-1}\right.$ ]

$k \quad$ turbulent kinetic energy $\left[\mathrm{m}^{2} \cdot \mathrm{s}^{-2}\right]$

$\dot{m}$ mass flow rate $\left[\mathrm{kg} \cdot \mathrm{s}^{-1}\right]$

$\dot{Q} \quad$ heat generation rate due to light absorption $\left[\mathrm{W} \cdot \mathrm{m}^{-2}\right.$ ]

$R e \quad$ Reynolds number $=\frac{\rho_{a} \bar{V}_{0} w_{\mathrm{DAG}}}{\mu_{a}}[-]$

$R i \quad$ Richardson number $=\frac{\left(\rho_{e}-\rho_{a}\right) g w_{D A G}}{\rho_{e} \bar{V}_{0}^{2}}[-]$

$S \quad$ source term

$T$ temperature $\left[{ }^{\circ} \mathrm{C}\right.$ or $\left.\mathrm{K}\right]$

$V \quad$ velocity magnitude $\left[\mathrm{m} \cdot \mathrm{s}^{-1}\right]$

$\bar{V} \quad$ mean velocity magnitude $\left[\mathrm{m} \cdot \mathrm{s}^{-1}\right]$

$u, v \quad$ air velocity in $x$ and $y$ directions, respectively $\left[\mathrm{m} \cdot \mathrm{s}^{-1}\right]$

$U$ heat transfer coefficient $\left[\mathrm{W} \cdot \mathrm{m}^{-2} \cdot \mathrm{K}^{-1}\right]$

$w \quad$ width $[\mathrm{m}]$

Greek symbols

$\Gamma \quad$ diffusivity coefficient $\left[\mathrm{m}^{2} \cdot \mathrm{s}\right.$

$\varepsilon \quad$ dissipation rate of $k\left[\mathrm{~m}^{2} \cdot \mathrm{s}^{-3}\right]$

$\lambda \quad$ thermal conductivity $\left[\mathrm{W} \cdot \mathrm{m}^{-1} \cdot \mathrm{K}^{-1}\right]$

$\mu \quad$ dynamic viscosity [Pa $\cdot \mathrm{s}]$

$\rho \quad$ density $\left[\mathrm{kg} \cdot \mathrm{m}^{-3}\right]$

$v \quad$ kinematic viscosity $\left[\mathrm{m}^{2} \cdot \mathrm{s}^{-1}\right]$

$\phi \quad$ generalized variable

\section{Subscripts}

a air

ar argon

cli cabinet light

d door

e external

eq equivalent

gap gap

gl glass 
rad radiation

rli room light

rms root-mean-square

Abbreviations

DAG Discharge Air Grille

RAG Return Air Grille

PBP Back Perforated Panel

\section{Introduction}

About $66-77 \%$ of the total heat load of open refrigerated display cabinets used in supermarkets were attributed to the entrainment of ambient warm and humid air into the system (Gaspar et al., 2011; Tassou et al., 2011). To address this issue, numerous studies have been carried out using both experimental and numerical approaches. It was found that air entrainment was promoted when the momentum effect increased whereas it became less pronounced when the buoyancy effect was dominant (Chen and Yuan, 2005). Because of the non-intrusive aspect and high spatial resolution accuracy, PIV measurement has become a technique used to study flow structures in various applications (Adrian, 2005). Field et al. (2002) implemented the PIV technique together with a hot wire anemometer to examine the entrainment characteristics of air curtains with a Reynolds $(R e)$ number range of 1500-8500 and a Richardson (Ri) number range of 0.13-0.58. The authors suggested that a decrease in $R e$ could reduce the amount of entrained air. However, this $R e$ must be above a critical value under which the air curtain integrity could not be ensured. This value depends on the specific design of each display cabinet. The effectiveness of the air curtain can also deteriorate as a result of external disturbances (Heidinger et al., 2015). Kaffel et al. (2015) performed experiments using both PIV and Laser Doppler velocimetry (LDV) techniques to demonstrate the effect of external lateral airflow on the effectiveness of the air curtain in a reduced-scale model of a display cabinet.

Because of the difficulties involved in experimental implementation, several numerical studies on open display cabinets have been carried out (Cortella et al., 2001; D'Agaro et al., 2006; Laguerre et al., 2012; Moureh and Yataghene, 2016). Ge and Tassou (2001) numerically studied the influence of design parameters and operating conditions on the air curtain performance: the width and length of the air jet, initial jet velocity (and turbulence), the position/dimensions of the return air grille (RAG). 


\section{Journal Pre-proof}

Foster et al. (2005) used a 3D-CFD model to study the airflow in an open display cabinet. These authors found that the inclination of the discharge air grille (DAG) has a significant effect on the air curtain performance to protect food in storage zone and the optimum angle depends on the width and the air velocity of the curtain. Navaz et al. (2005) combined both experimental (PIV and LDV) and numerical (CFD Fluent) approaches to determine the effect of design parameters on the air entrainment across the air curtain of an open display cabinet. The turbulence intensity, the shape of the velocity profile at the DAG and $R e$ were found to be the most significant parameters influencing the amount of air entrainment. Hammond et al. (2016) proposed a new design featuring multiple short air curtains for each shelf rather than a single long air curtain and reported a reduction in electricity consumption of $35.9 \%$ and a smaller range of maximum and minimum product temperatures (a difference of $9.5^{\circ} \mathrm{C}$ for the conventional design and $3.1^{\circ} \mathrm{C}$ for the short air curtain design).

Display cabinets retrofitted with doors constitute an energy saving alternative because they reduce the infiltration of external warm/humid air. Several studies have shown that a closed display cabinet generates 23-73\% energy savings (Evans, 2014; Fricke and Becker, 2010; Lindberg et al., 2010; Navigant Consulting Inc., 2009) and the presence of doors was found to have no impact on the sales volume (Fricke and Becker, 2010). Furthermore, doors can also provide better thermal comfort in retail stores due to less cold air spillage from the display cabinet (Lindberg et al., 2017). Given these advantages, display cabinets with doors have become default specification for new stores opened by various major retailers in Europe (EIA, 2017) and will account for about 75\% of total display cases in French supermarkets by 2020 (RPF, 2016). Faramarzi et al. (2002) reported that retrofitting a display cabinet with glass doors reduced the total cooling load by $68 \%$ and the average product temperature by $0.2{ }^{\circ} \mathrm{C}$. Likewise, Lindberg et al. (2010) observed that an overall air temperature reduction of at least 2 ${ }^{\circ} \mathrm{C}$ was achieved in the cabinet retrofitted with doors. Atilio de Frias et al. (2015) reported that the spatial temperature difference within the closed cabinet was $6{ }^{\circ} \mathrm{C}$ lower than that within the open one. To the best of the authors' knowledge, the study of airflow in a closed display cabinet is limited even though door installation can affect the airflow pattern in display cabinets, which in turn influences the heat transfer and product temperatures (Faramarzi et al, 2002). 


\section{Journal Pre-proof}

A review of the literature on experimental and numerical investigations of the performance of display cabinets was carried out by the authors (Chaomuang et al., 2017). An experimental study of heat transfer in a closed display cabinet was conducted and the effect of operating conditions on the product temperature was highlighted: room temperature, door-opening frequency and occupiedvolume percentage (Chaomuang et al., 2019a, 2019b). In order to build on our previous studies, the objectives of this study were:

- To conduct air velocity measurement in a display cabinet using the PIV technique. It is to be emphasized that the originality of our study is the measurement of unstable and low air velocity $\left(0<V_{a}<0.7 \mathrm{~m} \cdot \mathrm{s}^{-1}\right)$ in a closed cavity. Thus, several difficulties associated with implementation had to be overcome.

- To analyze the airflow pattern of a closed display cabinet.

- To develop a 2D-CFD model of a closed display cabinet in order to investigate the phenomena which are somewhat difficult to observe by the experiment (e.g. local air velocity near reflection area).

The thermal aspects were discussed based on the results obtained from previous studies (Chaomuang et al., 2019a, 2019b). The experimental and numerical methodologies developed in this study can be useful to scientists for understanding the phenomena and for the industry in order to improve the design under various operating conditions.

\section{Materials and methods}

\subsection{Refrigerated display cabinet}

A closed refrigerated display cabinet (Offlip 2 Eco 125S, Costan) equipped with an air curtain and two double-glazed glass doors was installed in a test room in which the temperature was controlled at 19 ${ }^{\circ} \mathrm{C}$. The storage compartment is composed of five shelves. Test product packages (made of methylcellulose) were fully loaded up to the net volume as shown in Fig. 1. Two axial fans under the bottom shelf provide air circulation in the display cabinet. After passing through an evaporator (situated behind the fans), air is blown along a vertical rear duct up to a discharge air grille (DAG) at 


\section{Journal Pre-proof}

which level the air curtain is established. This air curtain descends and covers the entire front area of the display cabinet. A perforated back panel (PBP) allows horizontal airflow from the back to join the air curtain at the front. At the bottom of the display cabinet, the air is driven through a return air grille (RAG), thus completing the airflow circuit. The characteristics of the cabinet and its components are given in Table 1.

To characterize experimentally the flow pattern inside a closed display cabinet, two conditions were studied: the refrigeration system was turned "off" and "on", while the cabinet fans operated continuously under both conditions. In such a manner, the influence of fans alone (the first condition) and combined fans/refrigeration (the second condition) on the airflow can be highlighted. For the studied display cabinet, there are 8-mm door gaps at the edges of the cabinet to assist door openings and facilitate defogging process on the glass doors after closing. Since these door gaps allow ambient air infiltration, the PIV measurement was additionally conducted to estimate the volumetric air infiltration rate through the gaps in this study.

\begin{tabular}{|l|l|}
\hline \multicolumn{2}{|l|}{ Table 1 - Characteristics of the closed refrigerated display cabinet used in the study } \\
\hline $\begin{array}{l}\text { Dimensions of the storage space } \\
\text { (width } \times \text { height } \times \text { depth) }\end{array}$ & $1250 \mathrm{~mm} \times 1345 \mathrm{~mm} \times 525 \mathrm{~mm}$ \\
\hline $\begin{array}{l}\text { Dimensions of shelves } \\
\text { - Shelves 1-4 }\end{array}$ & $1250 \mathrm{~mm} \times 25 \mathrm{~mm} \times 350 \mathrm{~mm}$ \\
Shelf 5 & $1250 \mathrm{~mm} \times 25 \mathrm{~mm} \times 475 \mathrm{~mm}$ \\
\hline Dimensions of a test product package & $200 \mathrm{~mm} \times 50 \mathrm{~mm} \times 100 \mathrm{~mm}$ \\
\hline Dimensions of a double-glazed door & $620 \mathrm{~mm} \times 1330 \mathrm{~mm} \times 22 \mathrm{~mm}$ \\
\hline Discharge air grille width & $50 \mathrm{~mm}$ \\
\hline Return air grille width & $30 \mathrm{~mm}$ \\
\hline $\begin{array}{l}\text { Dimensions of the perforated back panel } \\
(\text { width } \times \text { height } \times \text { thickness) }\end{array}$ & $1250 \mathrm{~mm} \times 1345 \mathrm{~mm} \times 3 \mathrm{~mm}$ \\
\hline $\begin{array}{l}\text { Perforation percentage of the back panel } \\
\text { (based on total panel area) }\end{array}$ & $\begin{array}{l}\text { Shelf 1: 2.3\% } \\
\text { Shelves 2-4: 3.8\% }\end{array}$ \\
\hline Number of propeller fans & Shelf 5: 8.3\% \\
\hline
\end{tabular}




\section{Journal Pre-proof}

\subsection{Air velocity measurement using PIV}

The air velocity measurement was performed using a two-dimensional PIV system (LaVision, FlowMaster 2D). The PIV system is composed of a double-pulsed Nd:YLF laser (527 nm wavelength, $10 \mathrm{~mJ}$ pulse energy, 0.2-20 kHz repetition rate), a 12-bit CMOS camera (HighSpeedStar 4G, $1024 \times$ 1024 pixels in resolution) equipped with a lens (Sigma, $105 \mathrm{~mm}, \mathrm{f} / 1: 2.8$ ) and a programmable timing unit for the synchronization of the device. To achieve light scattering, fine droplets of distilled water generated by a fogging system (Areco, model OD V7, with a median droplet diameter of $7 \mu \mathrm{m}$ ) were injected at the top and the back of the display cabinet. It should be emphasized that the experiment was conducted under the closed-door condition. Without opening and closing operations, the dew point temperature of the air was always lower than the inner temperature of the glass doors. Therefore, no fog deposition on the glass surfaces which can lead to an error of the PIV measurement. The overall experimental setup is illustrated in Fig. 1. PIV measurement was conducted on a center plane $(\mathrm{z}=520 \mathrm{~mm}$, Fig. 1) along the air curtain of the display cabinet. Image acquisition and postprocessing were conducted using a software package, DaVis 10.0.5. A comprehensive and more detailed explanation of the PIV measurement is widely available in the literature (Prasad, 2000; Raffel et al., 2018).

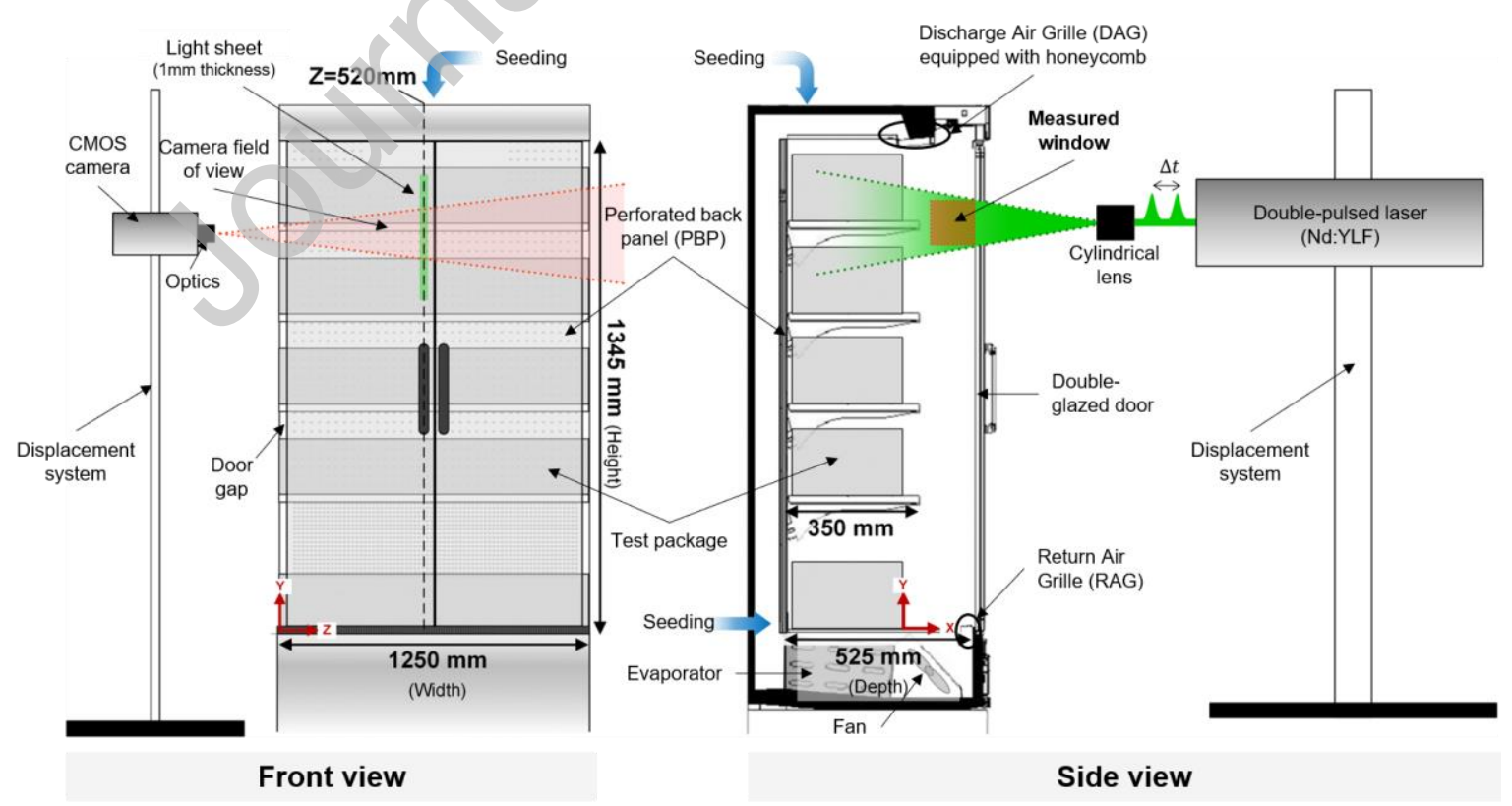

Fig. 1 Experimental setup for PIV measurement in a closed refrigerated display cabinet 


\subsubsection{Measurement procedure}

An entire measurement plane $(z=520 \mathrm{~mm}$, Fig. 1) was covered with 36 measured windows $(112 \mathrm{~mm}$ $\times 112 \mathrm{~mm}$ ) with a partial overlap between them. Every field of the camera view was calibrated previously by using a measuring tape and the DaVis software. This method is acceptable for image calibration of 2D-PIV applications (Harris, 2012). Moreover, the thinnest laser light sheet (about 1 $\mathrm{mm}$ ) was used in order to limit the image distortions due to the glass wall refractions. Because of the opaque door frame, the measurement was performed at $30 \mathrm{~mm}$ from the bottom shelf. The camera and the laser were mounted on a displacement system allowing the position of the measured windows to be changed (precision of displacement $\pm 1 \mathrm{~mm}$ ).

For each measured window, 1200 pairs of images were recorded at a frequency of $0.5 \mathrm{kHz}$. According to our sensitivity study, this number of pairs of images was optimal since it provided a reliable representation of mean velocity and other statistical information, i.e. mean and root-mean-square (rms) values not changed with higher number of pairs of images.

Note that the mean air velocity $(\bar{V})$ and the rms velocity fluctuation $\left(V_{r m s}\right)$ are given by

$$
\begin{aligned}
& \bar{V}=\frac{1}{N} \sum_{i=1}^{N} \sqrt{u_{i}^{2}+v_{i}^{2}} \\
& V_{r m s}=\sqrt{\frac{1}{N} \sum_{i=1}^{N}\left[\left(u_{i}-\bar{u}\right)^{2}+\left(v_{i}-\bar{v}\right)^{2}\right]}
\end{aligned}
$$

where $N$ is the total number of measured windows (1200 in our experiment); $u_{i}$ and $v_{i}$ are the air velocities in $x$ and $y$ directions measured at the instant $i$, respectively $\left[\mathrm{m} \cdot \mathrm{s}^{-1}\right]$

A multi-pass algorithm with decreasing interrogation area was used to process instantaneous vector calculation. Two passes were used with interrogation dimensions of $64 \times 64$ pixels and $32 \times 32$ pixels, respectively. Both passes were defined with $50 \%$ overlap. Given the interrogation dimensions of the second pass, the spacing between two calculated velocity vectors was 16 pixels (about $3.5 \mathrm{~mm}$ ) in both the horizontal and vertical directions. Any region near high reflection surface in the images (e.g. DAG, RAG, shelf edges and test packages) was always masked out and not included in the vector 


\section{Journal Pre-proof}

calculation. Referring to the guideline proposed by Keane and Adrian (1992), a time delay between two laser illuminations of $500 \mu$ s was the optimum for a good velocity estimation in our case since it allowed a mean particle displacement of less than $25 \%$ of the width of the interrogation window. After the mean velocity fields of all 36 measured windows were obtained, the entire measurement plane was established with the DaVis software by connecting all the windows together.

The measurement uncertainties were quantified by using a correlation statistics method (Sciacchitano and Wieneke, 2016). Overall, the uncertainty of the mean air velocity varied between 0.1 and $0.3 \%$ in most regions of interest and was slightly higher $(0.6 \%)$ in the mixing or shear layers and at the level of the bottom shelf, particularly near the RAG because of higher turbulence levels.

\subsection{Temperature measurement}

Reffering to our previsous study (Chaomuang et al., 2019a), the air and product temperatures were measured by using calibrated thermocouples $\left( \pm 0.2^{\circ} \mathrm{C}\right.$ accuracy $)$ in the middle section of a closed refrigerated display cabinet which operated under closed-door conditions and at a room temperature of $19{ }^{\circ} \mathrm{C}$ (humidity ratio of $0.003-0.004 \mathrm{~kg}$ of water $/ \mathrm{kg}$ of dry air). Timed-averaged temperatures were calculated over $5 \mathrm{~h}$ of quasi-steady state during which the defrosting period was excluded. The results of temperature measurements were used to compare with the numerical prediction of temperature distributions in the present study.

\section{Experimental results}

\subsection{Air velocity profiles in a closed display cabinet}

Figures $2 \mathbf{a}, \mathbf{2 b}$ and $\mathbf{2 c}$ show respectively the mean air velocity profiles, rms velocity fluctuations and velocity vector fields at the middle plane $(\mathrm{z}=520 \mathrm{~mm})$ of the display cabinet running only with fans (refrigeration system turned "off"). Figures 2d, 2e and $2 \mathbf{f}$ show the same parameters for the display cabinet running with fans and the refrigeration system turned "on". Because of high spatial resolution, only one of the eight vectors (in both $\mathrm{x}$ and $\mathrm{y}$ directions) is depicted in the velocity vector fields 


\section{Journal Pre-proof}

(Figures 2c and 2f). For better visibility of the flow pattern, some large arrows were manually superimposed on the fields.

When the refrigeration system was turned "off" (Fig. 2a), the inlet mean velocity magnitude of the jet normal to the DAG was approximately $0.57 \mathrm{~m} \cdot \mathrm{s}^{-1}$, corresponding to the $R e$ of about 2000 (based on the DAG width of $50 \mathrm{~mm}$ ). This $R e$ value was low compared with that of a typical open display cabinet (4200 and 8000, Field and Loth, 2006). From the DAG to the top shelf, the jet slightly accelerated because it was deviated by the test packages at the front. The jet then spread out and the velocity gradually decelerated due to the diffusion process - i.e. entrainment of neighboring air by the air jet. According to the discharge angle of the DAG (about $8^{\circ}$ relative to the vertical axis), the air flowed toward the door. Under the top shelf level $(\mathrm{y}<1120 \mathrm{~mm})$, the velocity profile showed a Coanda effect (jet adhesion to the wall) which caused relatively high velocity close to the door surface. The air velocity increased progressively when it flowed downward because of additional air flowing from the back through the PBP at each shelf, thereby enhancing the momentum flux along the flow path. Because of a higher percentage of perforated area on the PBP over the bottom shelf, higher air velocity can be clearly observed at this position. When it approached the RAG, the airflow was accelerated again by the fans.

High-velocity fluctuations were observed in two regions: the top and bottom parts of the cabinet (Fig. 2b). In the top parts near the DAG, high-velocity fluctuations can be explained by the development of eddies on both sides of the jet, i.e. in the mixing layers where high velocity gradient leads to large turbulent kinetic energy production. The fluctuations were further amplified because of the edge of the top shelf and the presence of the door which triggered air recirculation once air approached it. In the bottom part, fluctuations resulted from mixing between the back flow and the air curtain. Here, the flow was also turbulent in the air space above the test packages at the level of the bottom shelf and air recirculation also emerged near the front of the packages. Apart from these regions, small velocity fluctuations were observed. The vector field depicted in Fig. 2c shows the downward flow with recirculation at the front of the top shelf. 


\section{Journal Pre-proof}

A similar airflow pattern was observed in the display cabinet with the refrigeration system turned "on"

(Figures 2d, 2e and 2f) compared with the case in which the refrigeration system was turned "off"

(Figures 2a, 2b and 2c) despite slight discrepancies. The Coanda effect was less pronounced when refrigeration was applied because the air near the door surface had a relatively higher temperature, and thus an upward buoyancy force impeded downward flow for y $<1000 \mathrm{~mm}$. As shown in Fig. 2d, the velocity was relatively lower at the door when the refrigeration system of the display cabinet operated and reached its maximum near the shelf edges. Fig. 2e shows the same regions with relatively high velocity fluctuations in the case of the refrigeration system turned "off" (top and bottom parts), but higher turbulence was generated by interaction between the air curtain and the shelf edges. The vector field depicted in Fig. 2f shows similar flow patterns as in the case of the refrigeration system turned "off", with the exception of slightly more pronounced recirculation (upward flow) in the top part and the local maximum velocity situated at a greater distance from the door. 


\section{Journal Pre-proof}

(a)

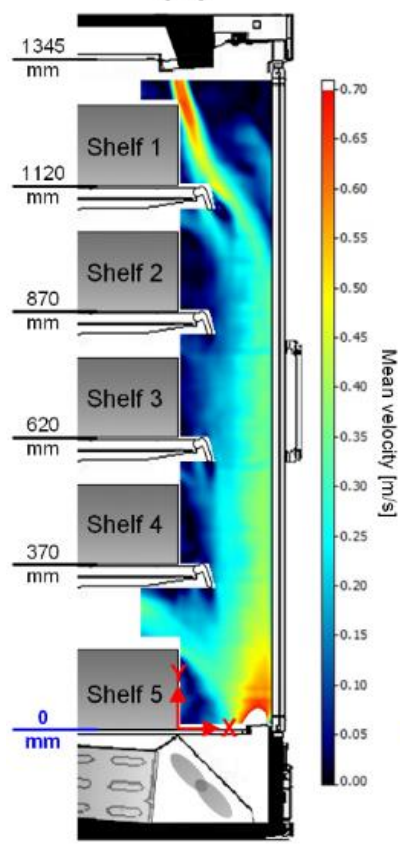

(d)

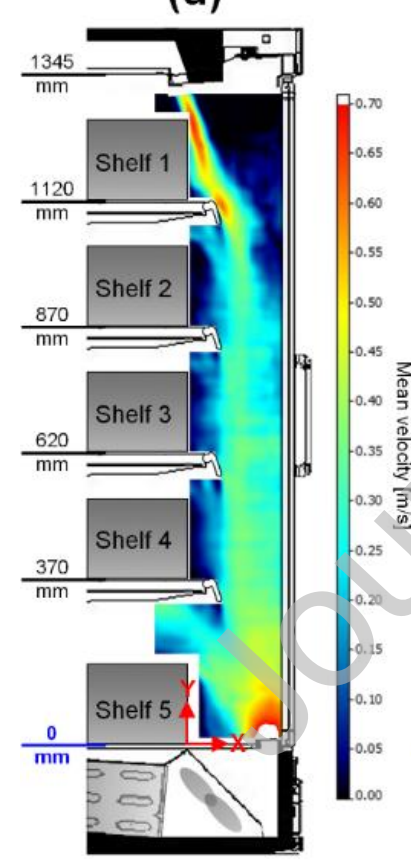

(b)

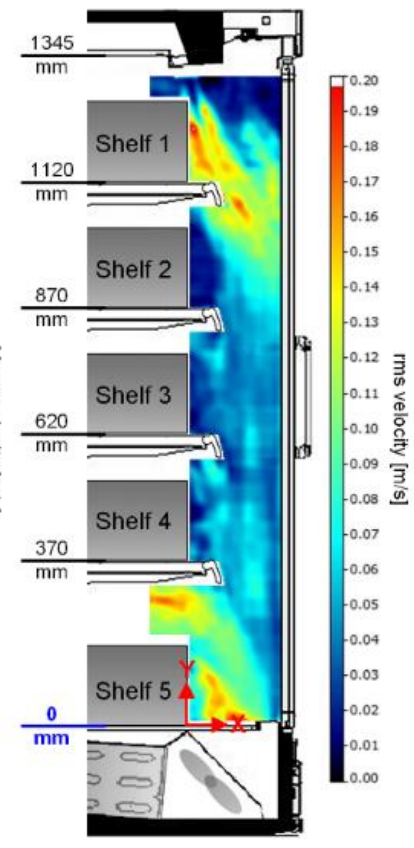

Without refrigeration

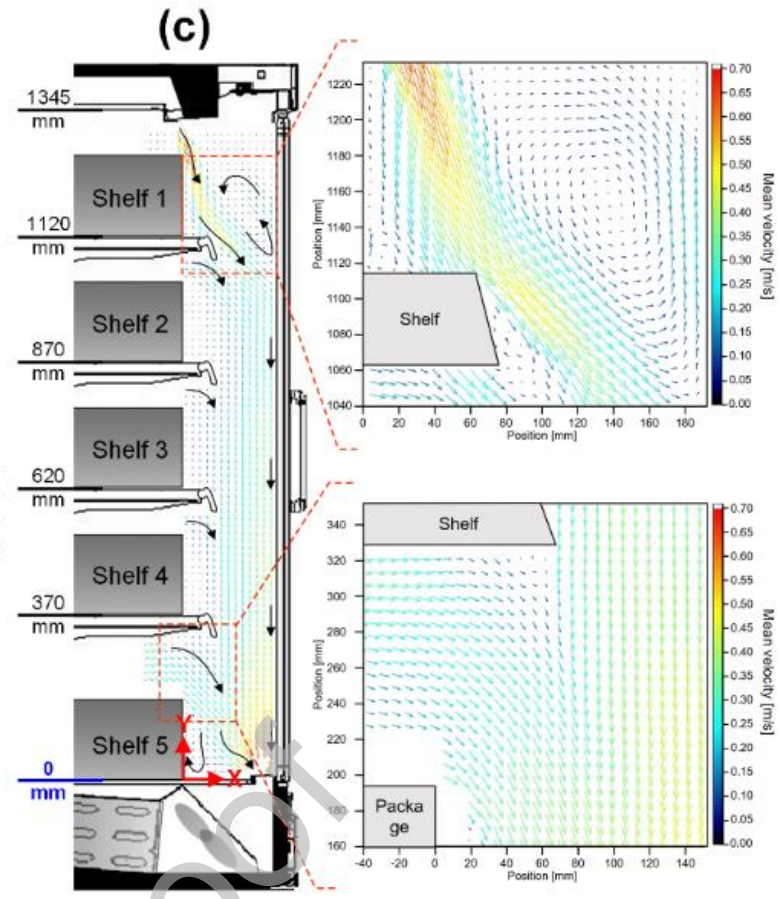

(e)
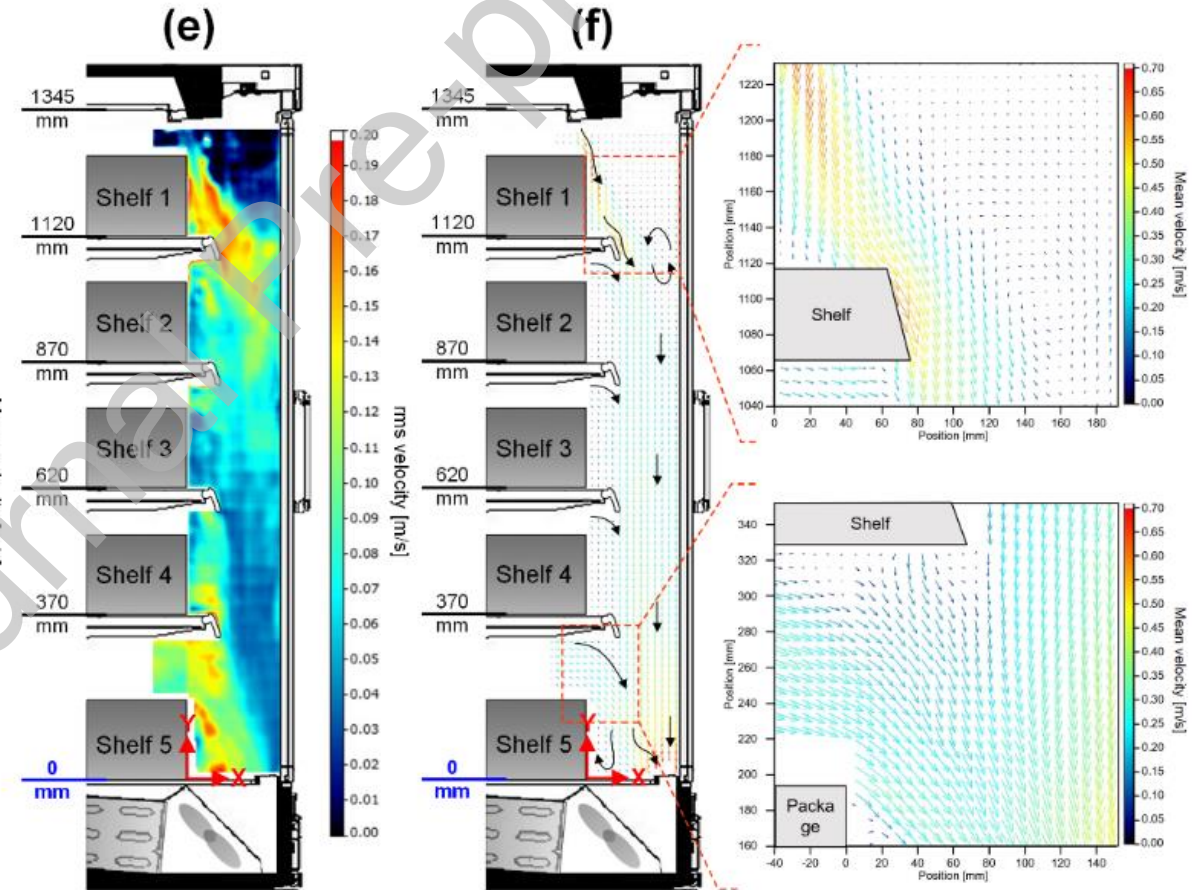

With refrigeration

Fig. 2. Mean air velocity profiles (a); velocity fluctuations (b); and velocity vector fields (c); along the air curtain of a closed display cabinet running with fans only (refrigeration system "off"). Mean air velocity profiles (d); velocity fluctuations (e); and velocity vector fields (f); along the air curtain of a closed display cabinet running with fans and the refrigeration system "on". 


\subsection{Ambient air infiltration through door gaps}

For the studied display cabinet, there are 8-mm door gaps at both edges of the cabinet, on one hand this is to assist door openings. On the other hand, these door gaps can facilitate defogging process on the glass doors (D'Agaro et al., 2006). Warm air inflow and cold outflow through the gaps were observed in our previous study (Chaomuang et al., 2019a). A PIV measurement was additionally conducted in the middle of the left door gap throughout the height of the door to quantify the volumetric air infiltration rate through the gaps $(8 \mathrm{~mm}$ in width). The refrigeration system was turned on during this experiment. In fact, there is also a gap between the two doors, but it is small $(<2 \mathrm{~mm})$, compared to the other ones at the cabinet edges. Regarding this, the gap between the doors was not taken into account for the calculation of the air infiltration rate. The experimental result showed that the air inflow emerged at $y>1060 \mathrm{~mm}$ while the air outflow took place at the lower extent of the gap. By integration of the positive horizontal velocity component $(u)$ over the height of the door, the volumetric air infiltration rate through the gaps was estimated to be approximately $0.0029 \mathrm{~m}^{3} \cdot \mathrm{s}^{-1}$. It was assumed that the amount of outflow air was replaced by the ambient air infiltration and the rates of the air infiltration through the door gaps on the left and the right sides were the same. This result suggested that air infiltration under closed-door conditions accounted for about $8 \%$ of the supply air from the DAG, which is much less than the case of open display cabinets $(\sim 30-40 \%$, Amin et al., 2009).

\subsection{Internal temperature distribution}

The average air and product (core) temperatures in the middle plane of the closed display cabinet were depicted Fig. 3. This experimental result was taken from our previous study (Chaomuang et al., 2019a). It was found that the products at the front of the top shelf had the highest temperature (about 2.3-2.4 ${ }^{\circ} \mathrm{C}$ ) whereas the products at the back of the bottom shelf had the lowest temperature (about $\left.0.5^{\circ} \mathrm{C}\right)$. The high temperature on the top shelf can be explained by the interdependencies among various influencing factors. One of these factors was the interaction between the air recirculation and the ambient air infiltration at the top shelf level as observed by the PIV measurement. This led to an increase in the air curtain temperature, thus high product temperature at this position. In addition to 


\section{Journal Pre-proof}

this factor, the high product temperature could result from heat loss through the glass doors, less cold air from the back due to low percentage of perforation area (2.3\%, Table 1) over the top shelf as well as the vicinity of the cabinet light. Because of higher percentage of perforation areas, lower product temperatures at the front of the lower shelves were observed. Much lower product temperature was found at the back of every shelf. This resulted from a combination of convection between product and cold air coming from the PBP and conduction within and between the products.

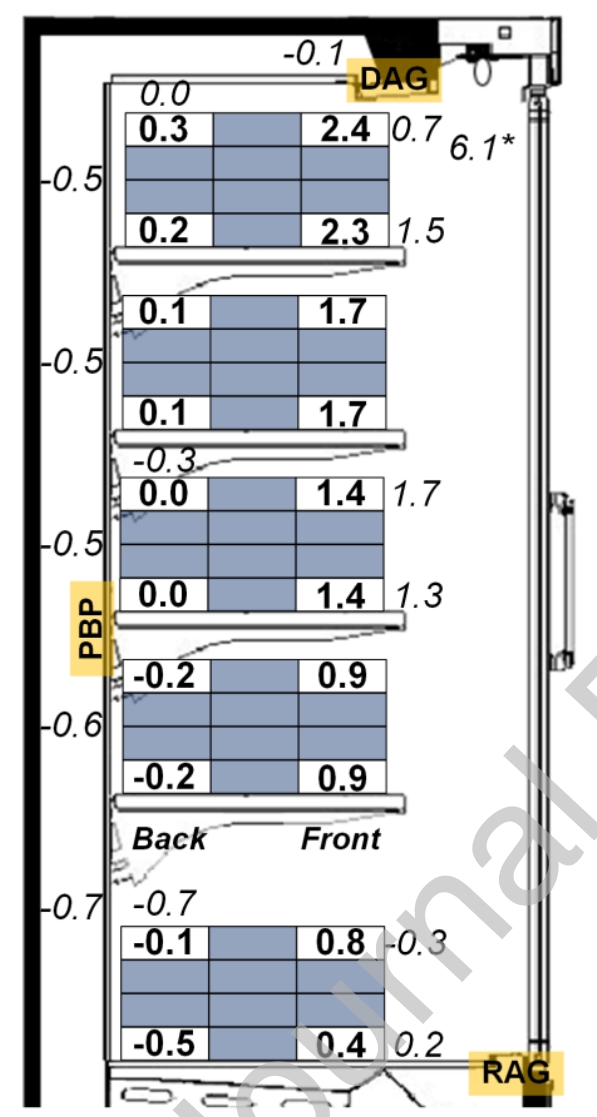

Italic values - Air temperature in the rear duct and at $20 \mathrm{~mm}$ from the product surface (*at $100 \mathrm{~mm}$ )

Bold values - Product core temperature

Fig. 3 Experimental result of air and product temperature distributions in a closed display cabinet (Chaomuang et al., 2019a).

From a thermal point of view for the closed display cabinet, there is a small amount of convective exchange with the external ambient air through the door gaps. The conduction and radiation exchanges through the doors are limited by the presence of double-glazing windowpanes coated with lowinfrared emissivity materials. In addition, the low velocity fluctuations near the door reduce the 
convective heat transfer between the inner side of the door and the air curtain. The air entrained by the air jet at the top shelf level comes mainly from air recirculation near the door and it causes high air temperature at this position (about $6{ }^{\circ} \mathrm{C}$, Fig. 3). In case of open display cabinets, the ambient air infiltration emerges across the air curtain. This ambient air is engulfed at the outer layer of the air curtain via large unsteady eddies (Moureh and Yataghene, 2016), thus relatively high air temperature, compared to the closed cabinet. Moreover, there is no radiation shield between the external walls located at the front of the open display cabinet and the front products. These findings explain better thermal performance observed in closed display cabinets, compared with open ones (Chaomuang et al., 2019a).

\section{CFD modeling}

A two-dimensional CFD model was developed to investigate the airflow and its influence on the temperature distribution in the closed display cabinet. The main objective is not to simulate precisely all the flow and transfer details. Instead, the aim was to examine the capability of a $2 \mathrm{D} k-\varepsilon$ model to reproduce the main phenomena and to predict the product temperatures in the display cabinet with acceptable accuracy. An example of more precise models with a three-dimensional large-eddy simulation (LES) can be found in Moureh and Yataghene (2017). The prediction of velocity profile with the refrigeration system turned "on" was compared with the results obtained from the PIV measurements. As presented in Section 3.3, the results of temperature measurements conducted in our previous study (Chaomuang et al., 2019a) were used to compare with the numerical prediction of temperature distributions in the present study.

\subsection{Geometry and mesh details}

The dimensions used for the 2D model were those of the real closed display cabinet (Table 1) and only the internal storage space of the cabinet was considered in the computational domain (Fig. 4). The domain consisted of fluid and solid regions, representing airflow and products in the cabinet, respectively. An incompressible ideal gas was used for the fluid region while the thermal properties of methylcellulose were specified for the solid region $\left(\right.$ density $=1071 \mathrm{~kg} \cdot \mathrm{m}^{-3}$; thermal conductivity $=$

$0.510 \mathrm{~W} \cdot \mathrm{m}^{-1} \cdot \mathrm{K}^{-1}$; heat capacity $=3372 \mathrm{~J} \cdot \mathrm{kg}^{-1} \cdot \mathrm{K}^{-1}$, Icier and Ilicali, 2005). Both unstructured and 


\section{Journal Pre-proof}

structured meshes were used for the entire domain. Much finer meshes were particularly defined in the regions near the DAG, the RAG and the solid/fluid interfaces. Several models with different mesh sizes (M1-M3, Fig. 5) were preliminarily tested for the grid independence study so that numerical accuracy was ensured. It was found that the mesh M2 with 134,968 nodes and 97,693 elements was satisfactory since the numerical results did not change when the mesh size increased. This mesh was used in all calculations. It needs to be noted that Fig. $\mathbf{5}$ is only an example of mesh comparison. Other velocity and temperature profiles were also considered both in the air curtain and above the product of every shelf. Between the mesh M2 and M3, the differences in the average air velocity, the air temperature and the product temperature in the whole computational domain was less than $0.0001 \mathrm{~m} \cdot \mathrm{s}^{-}$ ${ }^{1}, 0.0004{ }^{\circ} \mathrm{C}$ and $0.04{ }^{\circ} \mathrm{C}$, respectively. The simulation was driven using a computer server (Dell, Precision 3620, 64-bit operating system) with Intel Xeon E3-1240 Quad Core running at $3.50 \mathrm{GHz}(8$ Mb internal cache) and 64 Gb RAM. The computational time was four hours for the mesh used.

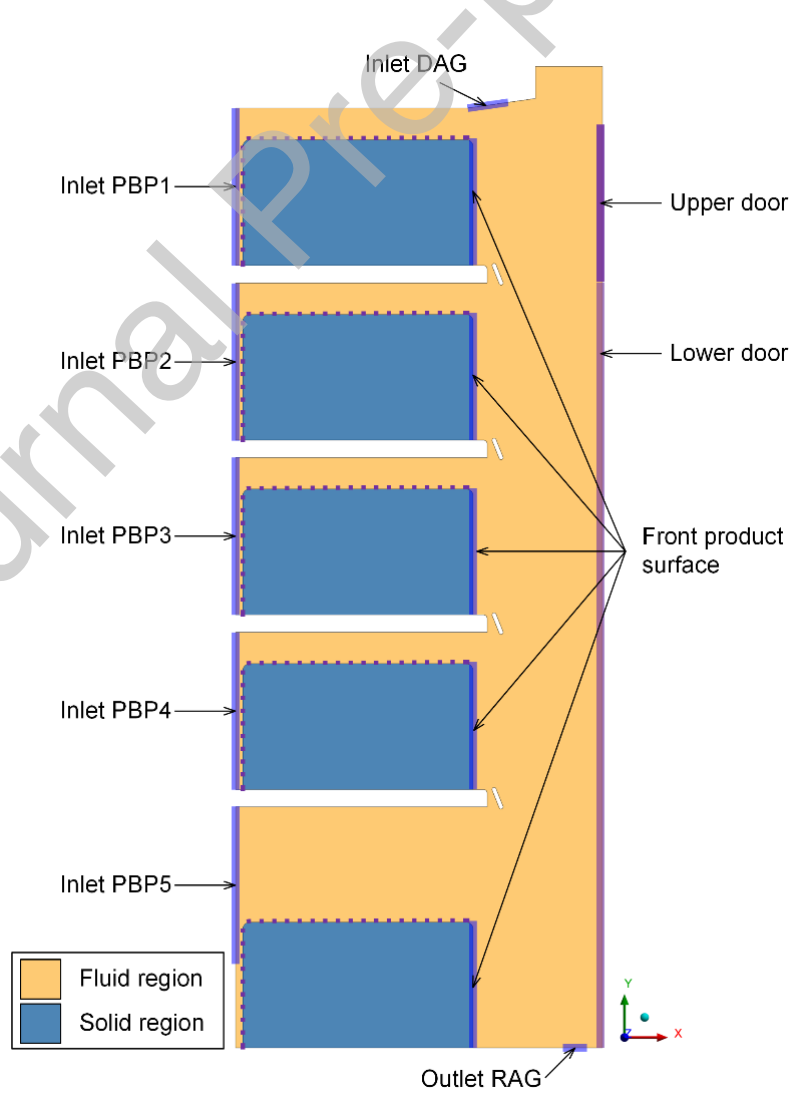

Fig. 4 The computational domain of the 2D-CFD model for a closed display cabinet and the locations of boundary conditions. 

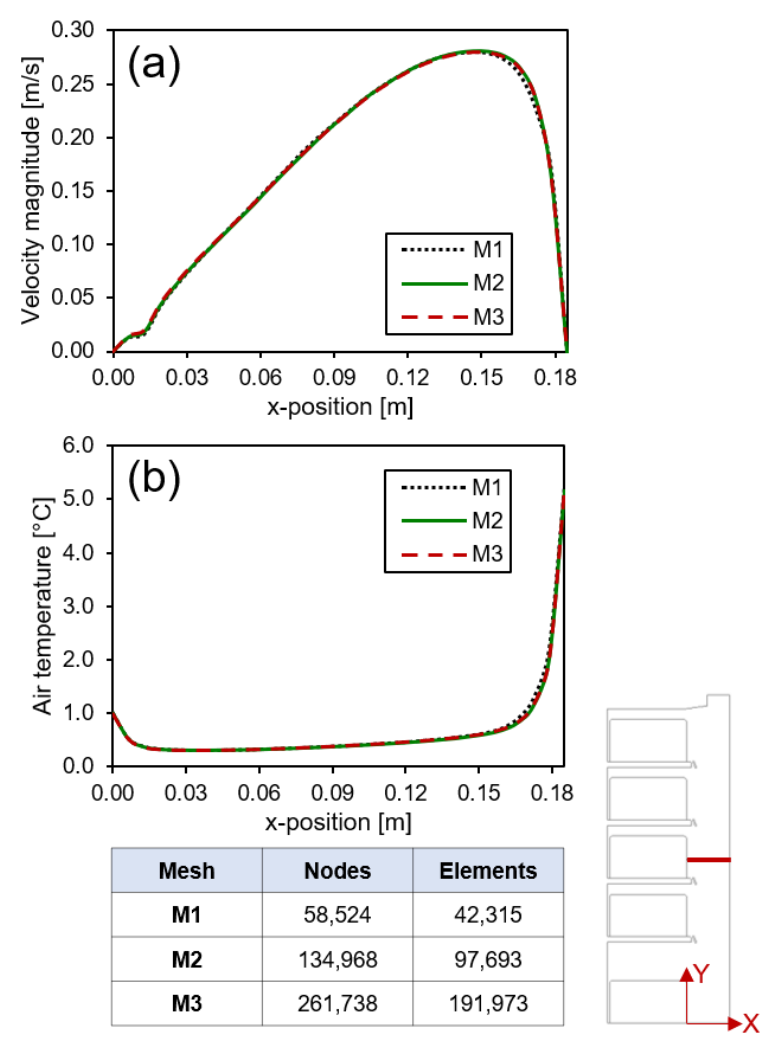

Fig. 5 Velocity profiles (a) and temperature profile (b) in front of Shelf 3 for different meshes.

\subsection{Mathematical description}

The CFD model in steady state was developed by using commercial ANSYS Code Fluent 17.2 software. The model is based on solving the governing equations which consist of the conservation of mass, momentum and energy equations (Versteeg and Malalasekera, 2007). Since the flow is turbulent, these governing equations are time-averaged (Reynolds-averaged Navier-Stokes, RANS) and the standard k- $\varepsilon$ turbulence model was used together with these equations. Note that turbulence was firstly modeled with other k- $\varepsilon$ turbulence models (i.e. Renormalization Group (RNG) and Realizable) and the results obtained were found to be almost identical. The standard k- $\varepsilon$ turbulence model was therefore used as it was the best compromise between accuracy and reasonable computational time. The model also used an enhanced wall treatment function in conjunction with the turbulence model to take into account viscous effects near the walls. For 2D, steady-state and incompressible fluid flow, the general form of the governing equations can be written as 
$\frac{\partial(\rho u \phi)}{\partial x}+\frac{\partial(\rho v \phi)}{\partial y}=\frac{\partial}{\partial x}\left(\rho \Gamma_{\phi} \frac{\partial \phi}{\partial x}\right)+\frac{\partial}{\partial y}\left(\rho \Gamma_{\phi} \frac{\partial \phi}{\partial y}\right)+S_{\phi}$

where $\phi$ is a generalized transport variable, $\Gamma_{\phi}$ and $S_{\phi}$ are respectively the diffusion coefficient and the source term for the corresponding transport variable $\phi$. The complete description of these equations can be found in Tu et al. (2018).

\subsection{Boundary conditions}

Fig. 4 shows the locations of boundary conditions imposed in the computational domain. Values used for boundary conditions were taken from the experimental data presented in this present study and in our previous work (Chaomuang et al., 2019a).

\subsubsection{Inlet boundary conditions}

Six velocity inlet boundary conditions were imposed in the computational domain: one inlet for the flow at the DAG and the other five inlets for the flow from the PBP at the levels of different shelves (Fig. 4). Uniform velocity profile and a direction normal to the inlet were assumed under all inlet boundary conditions. The velocity inlet at the DAG was the mean velocity magnitude obtained from the PIV measurement. The experimental results could not be used because of the measurement position was slightly far from the DAG $(5 \mathrm{~cm})$. The velocities at the PBP inlets were estimated based on the air distribution percentages (Chaomuang et al., 2019a) for each shelf. They represent the airflow rate averaging through the PBP at a given shelf divided by the total flow rate in the display cabinet. Given the velocity magnitude at the DAG, the corresponding velocities over these shelves were determined. The measured temperatures were applied for thermal boundary conditions. All the inlet boundary condition values are summarized in Table 2 .

\begin{tabular}{|l|c|c|c|c|c|c|c|}
\hline Table 2 - Inlet boundary conditions \\
\hline \multirow{2}{*}{ Parameter } & Unit & \multirow{2}{*}{ DAG } & \multicolumn{5}{|c|}{ PBP } \\
\cline { 4 - 8 } & & Shelf 1 & Shelf 2 & Shelf 3 & Shelf 4 & Shelf 5 \\
\hline $\begin{array}{l}\text { Air distribution } \\
\text { percentage }\end{array}$ & $\%$ & 50 & 2 & 2 & 3 & 5 & 38 \\
\hline Velocity $^{(\mathrm{a})}$ & $\mathrm{m} \cdot \mathrm{s}^{-1}$ & 0.57 & 0.005 & 0.005 & 0.008 & 0.013 & 0.096 \\
\hline Temperature $^{(\mathrm{a})}$ & ${ }^{\circ} \mathrm{C}$ & -0.1 & -0.5 & -0.5 & -0.5 & -0.6 & -0.7 \\
\hline Turbulent intensity $^{(\mathrm{b})}$ & $\%$ & 3 & 5 & 5 & 5 & 5 & 5 \\
\hline
\end{tabular}


$U_{d, e q}=U_{d}+\frac{\dot{m}_{g a p} C_{p}}{A_{d}}=12.7 \mathrm{~W} \cdot \mathrm{m}^{-2} \cdot \mathrm{K}^{-1}$

where $A_{d}$ is the area of the upper part of the door (Fig. 4).

The other walls were considered as adiabatic.

\section{Numerical results}

\subsection{Air velocity profile}

The air velocity profile of the closed display cabinet with the refrigeration system turned "on" are shown in Fig. 6. The air curtain formed at the DAG was deviated to the door as it descended to the RAG. A large air recirculation region was observed in the upper part of the cabinet and some small recirculation regions were also detected around product packages (the phenomenon cannot be observed by the experiment due to high reflection surface). Near the DAG, the edge effect of the package on the top shelf caused a slight increase in the jet velocity. The diffusion process at the shear layer between the air curtain and the adjacent air caused a velocity decrease when flowing downward. Beyond the mid-height between Shelves 1 and 2, the air velocity was maintained because the air curtain momentum was strengthened by the air flowing from the PBP. Unlike the open display cabinet, the thickness of the air curtain in the closed display cabinet was limited by the presence of the doors. Thus, flow integrity was preserved. The maximum velocity was close to the door due to the Coanda effect. Since the mass flow rate gradually increased along the flow path, relatively high velocity was observed near the RAG. In comparison with the experimental results (Section 3.1), the developed model can reproduce the main phenomena of the flow distributions in the closed display cabinet (Fig. 6a). Moreover, the trends and orders of magnitude were similar between 2D-CFD predictions and experiments with the mean absolute difference of $0.06 \mathrm{~m} / \mathrm{s}$ in velocity (Fig. $6 \mathbf{b}$ ). 


\section{Journal Pre-proof}

(a)

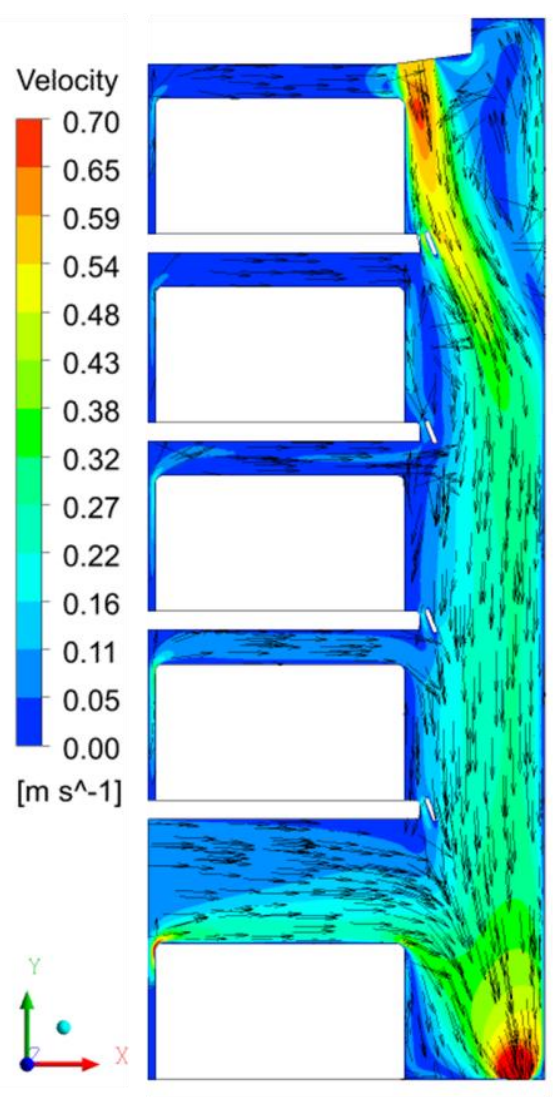

(b)
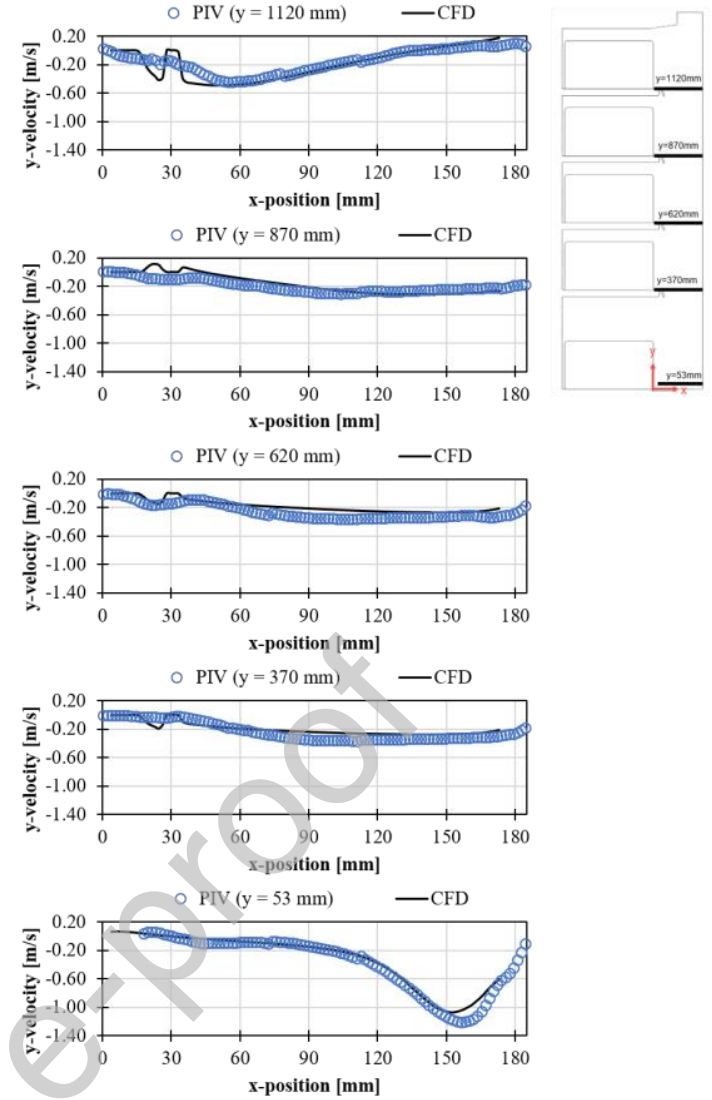

Fig. 6 (a) Predicted air velocity profile in a closed refrigerated display cabinet (b) comparison between experimental (PIV) and numerical (CFD) results.

\subsection{Air and product temperature distributions}

Fig. 7 depict the results of air and product temperature distributions obtained from the numerical prediction. Overall, the predicted air and product temperature distributions showed relatively good agreement with the experimental data as presented in Section 3.3. For both experimental and numerical results, the air temperature was lower than $2.0{ }^{\circ} \mathrm{C}$ everywhere, except in the upper part beyond the air curtain. At this position, the air temperature recorded at a measurement point was 6.1 ${ }^{\circ} \mathrm{C}\left(\right.$ Fig. 3) whereas the simulated temperature did not exceed $4{ }^{\circ} \mathrm{C}$ (Fig. 7). This discrepancy could be explained by the fact that air infiltration through the door gaps was simply taken into account by using an equivalent heat transfer coefficient at the upper part of the door. 


\section{Journal Pre-proof}

Nevertheless, the model allows the prediction of the product temperature ranges and the trends. The mean absolute differences between the prediction and measurement were $1.1{ }^{\circ} \mathrm{C}$ in the air temperature and $0.5{ }^{\circ} \mathrm{C}$ in the product temperature. Temperature heterogeneity was observed between products located at the front and the back of the shelves. The higher product temperature at the front resulted from the heat exchanges with the air curtain which was warmer than the air coming from the PBP and (visible) radiation absorption due to the lights. Due to the proximity to the cabinet lights, the product at the front of the top shelf was the product with the highest temperature. The lowest product temperature was at the back of the bottom shelf because heat exchange was mainly governed by convection with the cold air from the PBP and conduction within the products. Since the cold air flowed from the PBP into the bottom shelf with a relatively higher mass flow rate (highest perforation percentage), the product at the back of the bottom shelf had the lowest temperature.

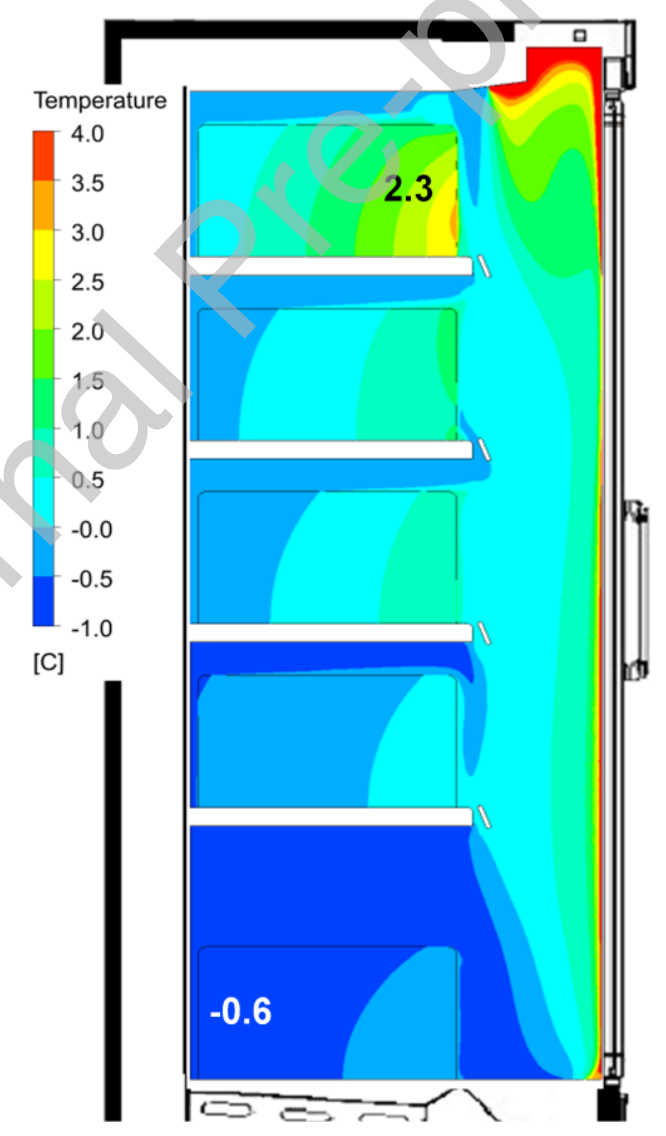

Fig. 7 Numerical prediction of the internal temperature distribution in a closed display cabinet

\section{Conclusions}




\section{Journal Pre-proof}

Air velocity measurements using the PIV technique were conducted in a closed display cabinet and open-door with a $90^{\circ}$ opening angle. According to the studied closed display cabinet, the $R e$ (based on the DAG width) was approximately 2000. In the closed configuration, similar flow phenomena were observed in the case of the refrigeration system turned "off" or "on" despite small discrepancies. The air curtain deviated to the door through a Coanda effect. However, it was less pronounced in the case of the refrigeration system turned "on" for which the upward buoyancy force impeded the downward flow. The air curtain was quite stable in most regions, with the exception of the top and the bottom of the cabinet where relatively high velocity fluctuations occurred. At the top of the cabinet, air recirculation occurred and could have promoted ambient air infiltration through the door gaps. In the open configuration, large unsteady eddies developed in the outer mixing layers of the air curtain, causing the ambient air to be entrained in the curtain. Comparison between the flow patterns in the closed and open configurations leads to the conclusion that products would be better protected in closed display cabinets.

A steady-state 2D-CFD model with the standard $\mathrm{k}-\varepsilon$ turbulence model was also developed in this study to investigate the airflow and its influence on the thermal distributions in a closed display cabinet. Despite its simplifications, the model has shown the ability to reproduce the main flow phenomena observed by the experiments. The predicted product temperature profile trend also agreed with the experimental data. In future studies, the developed model will be used to examine the influences of unexplored design parameters and the operating conditions on the air and product temperature distributions such as airflow rate, air temperature at the DAG and product occupied volume.

Even though a specific display cabinet was used, the results provide general information on the phenomena occurring in the display cabinet. The presence of doors causes air recirculation which could induce the infiltration of warm air through the door gaps. Sealing these gaps would certainly mitigate this issue. Nonetheless, the design of closed display cabinets should probably be revisited. For example, the air curtain might not be necessary due to the replacement of the physical barriers. 


\section{Declaration of Competing Interest}

The authors declare that they have no known competing financial interests or personal relationships that could have appeared to influence the work reported in this paper.

\section{Acknowledgment}

This research was funded by King Mongkut's Institute of Technology Ladkrabang, Thailand, National Research Institute of Science and Technology for Environment and Agriculture, France, and the French Embassy in Thailand.

\section{References}

Adrian, R.J., (2005). Twenty years of particle image velocimetry. Experiments in Fluids 39(2), 159169.

Amin, M., Dabiri, D., Navaz, H.K., (2009). Tracer gas technique: A new approach for steady state infiltration rate measurement of open refrigerated display cases. Journal of Food Engineering 92(2), 172-181.

Chaomuang, N., Flick, D., Denis, A., Laguerre, O., (2019a). Experimental analysis of heat transfer and airflow in a closed refrigerated display cabinet. Journal of Food Engineering 244, 101-114.

Chaomuang, N., Flick, D., Denis, A., Laguerre, O., (2019b). Influence of operating conditions on the temperature performance of a closed refrigerated display cabinet. International Journal of Refrigeration.

Chaomuang, N., Flick, D., Laguerre, O., (2017). Experimental and numerical investigation of the performance of retail refrigerated display cabinets. Trends in Food Science \& Technology 70(Supplement C), 95-104.

Chen, Y.-G., Yuan, X.-L., (2005). Experimental study of the performance of single-band air curtains for a multi-deck refrigerated display cabinet. Journal of Food Engineering 69(3), 261-267.

Cortella, G., Manzan, M., Comini, G., (2001). CFD simulation of refrigerated display cabinets. International Journal of Refrigeration 24(3), 250-260.

D'Agaro, P., Cortella, G., Croce, G., (2006). Two- and three-dimensional CFD applied to vertical display cabinets simulation. International Journal of Refrigeration 29(2), 178-190.

D’Agaro, P., Croce, G., Cortella, G., 2006. Numerical simulation of glass doors fogging and defogging in refrigerated display cabinets. Applied Thermal Engineering 26, 1927-1934.

EIA, (2017). Chilling Facts VII: Are Europe's supermarkets ready to quit HFCs? Environmental Investigation Agency.

Evans, J.A., (2014). Are Doors on Fridges the Best Environmental Solution for the Retail Sector? The Institute of Refrigeration, London, UK.

Faramarzi, R.T., Coburn, B.A., Sarhadian, R., (2002). Performance and energy impact of installing glass doors on an open vertical deli/dairy display case. ASHRAE Transactions 108, 673. 
Field, B.S., Loth, E., (2006). Entrainment of refrigerated air curtains down a wall. Experimental Thermal and Fluid Science 30(3), 175-184.

Field, B.S., Loth, E., Hrnjak, P., (2002). Entrainment in refrigerated air curtains. Air Conditioning and Refrigeration Center. College of Engineering.

Foster, A.M., Madge, M., Evans, J.A., (2005). The use of CFD to improve the performance of a chilled multi-deck retail display cabinet. International Journal of Refrigeration 28(5), 698-705.

Fricke, B., Becker, B., (2010). Energy use of doored and open vertical refrigerated display cases, International Refrigeration and Air Conditioning Conference. Purdue University, West Lafayette, IN, USA.

Gaspar, P.D., Carrilho Gonçalves, L.C., Pitarma, R.A., (2011). Experimental analysis of the thermal entrainment factor of air curtains in vertical open display cabinets for different ambient air conditions. Applied Thermal Engineering 31(5), 961-969.

Ge, Y.T., Tassou, S.A., (2001). Simulation of the performance of single jet air curtains for vertical refrigerated display cabinets. Applied Thermal Engineering 21(2), 201-219.

Hammond, E., Marques, C., Ketteringham, L., (2016). Application of short air curtain in retail display refrigerators, 4th IIR Conference on Sustainability and the Cold Chain, Auckland, New Zealand.

Harris, J. R. (2012). Investigation of Relative Importance of Some Error Sources in Particle Image Velocimetry. (Master's thesis), Utah State University.

Heidinger, G., Nascimento, S., Gaspar, P., Silva, P., (2015). Experimental study of the influence of consumers' movement parallel to the frontal opening of a multideck display case on the evaporator's thermal performance, Proceedings of the 24th IIR International Congress of Refrigeration.

Icier, F., Ilicali, C., (2005). The use of tylose as a food analog in ohmic heating studies. Journal of Food Engineering 69(1), 67-77.

Illuminating Engineering Society of North America, (1991). Recommended Practice for Lighting Merchandising Areas: A Store Lighting Guide Y1. Journal of the Illuminating Engineering Society 20(1), 161-222.

Kaffel, A., Moureh, J., Harion, J.-L., Russeil, S., (2015). Experimental investigation of a plane wall jet subjected to an external lateral flow. Experiments in Fluids 56(5).

Keane, R.D., Adrian, R.J., (1992). Theory of cross-correlation analysis of PIV images. Applied Scientific Research 49, 191-215.

Laguerre, O., Hoang, M.H., Flick, D., (2012). Heat transfer modelling in a refrigerated display cabinet: The influence of operating conditions. Journal of Food Engineering 108(2), 353-364.

Lindberg, U., Axell, M., Fahlén, P., (2010). Vertical display cabinets without and with doors-a comparison of measurements in a laboratory and in a supermarket, 1st IIR International Conference on Sustainability and the Cold Chain, Cambridge, United Kingdom.

Lindberg, U., Fahlén, P., Axell, M., Fransson, N., (2017). Thermal comfort in the supermarket environment - multiple enquiry methods and simultaneous measurements of the thermal environment. International Journal of Refrigeration 82, 426-435.

Moureh, J., Yataghene, M., (2016). Numerical and experimental investigations on jet characteristics and airflow patterns related to an air curtain subjected to external lateral flow. International Journal of Refrigeration 67, 355-372.

Moureh, J., Yataghene, M., (2017). Large-eddy simulation of an air curtain confining a cavity and subjected to an external lateral flow. Computers \& Fluids 152, 134-156. 


\section{Journal Pre-proof}

Navaz, H.K., Henderson, B.S., Faramarzi, R., Pourmovahed, A., Taugwalder, F., (2005). Jet entrainment rate in air curtain of open refrigerated display cases. International Journal of Refrigeration 28(2), 267-275.

Navigant Consulting Inc., (2009). Energy Savings Potential and R\&D Opportunities for Commercial Refrigeration Final Report, Energy Efficiency and Renewable Energy Building Technologies Program. U.S. Department of Energy.

Prasad, A.K., (2000). Particle image velocimetry. Current Science 79(1), 51-60.

Raffel, M., Willert, C.E., Scarano, F., Kähler, C.J., Wereley, S.T., Kompenhans, J., (2018). Particle image velocimetry: a practical guide. Springer.

RPF, (2016). Fermeture des meubles réfrigérés: du positif pour les clients, La Revue Pratique du Froid et du Conditionnement d'Air. Imprimerie Chirat, St-Just-la-Pendue, pp. 26-28.

Sciacchitano, A., Wieneke, B., (2016). PIV uncertainty propagation. Measurement Science and Technology 27(8), 084006.

Tassou, S.A., Ge, Y., Hadawey, A., Marriott, D., (2011). Energy consumption and conservation in food retailing. Applied Thermal Engineering 31(2-3), 147-156.

Tu, J., Yeoh, G.H., Liu, C., (2018). Computational fluid dynamics: a practical approach. ButterworthHeinemann.

Versteeg, H.K., Malalasekera, W., (2007). An introduction to computational fluid dynamics: the finite volume method. Pearson education. 